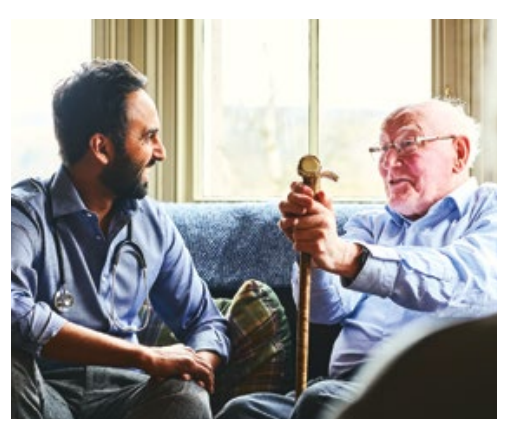

CPD

Michael Tran, Matthew Grant, Josephine Clayton, Joel Rhee

\section{Background \\ Advance care planning (ACP) is an important component of quality care for patients with chronic and advanced diseases. General practititoners are ideally placed to initiate ACP because of their role in care coordination of chronic and advanced diseases, and the longstanding relationship they develop with patients.}

\section{Objectives}

This paper outlines the key barriers to general practice involvement in ACP and describes useful strategies for incorporating ACP into patient care.

\section{Discussion}

Barriers to ACP are many and involve health professionals, patients and the healthcare system. To successfully incorporate ACP into patient care, there should be: (i) a commitment from the whole practice to incorporate ACP into patient care; (ii) a focus on building capacity for ACP in the practice; and (iii) efforts to implement and optimise the process of ACP. The outcomes of ACP (eg Advance Care Directives) should be disseminated appropriately to enable them to improve patient care.

\title{
Advance care decision making and planning
}

ADVANCE CARE PLANNING (ACP) is a process of reflection, discussion and communication that enables a person to plan for their future medical treatment and other care, at a time when they are unable to make, or communicate, decisions for themselves. ${ }^{1}$ In discussion with clinicians, family members and important others, ACP may result in the completion of written documents that can take a number of formats with differing legal status (Box 1).

\section{Why general practitioners should engage in ACP}

Australia's population is both growing and ageing. Currently, $15 \%$ of the population is aged 65 years and over ( 3.7 million) and this number is projected to increase to $19 \%$ by $2031 .^{2}$ An increasing number of Australians also live in residential aged care homes at the end of their lives, with only $14 \%$ dying outside of hospital or residential aged care in the first decade of the 21 st century. ${ }^{3}$ In their last year of life, Australians with advanced progressive diseases will have an average of eight hospital admissions ${ }^{4}$ and a $60-70 \%$ chance of dying in the hospital. ${ }^{5}$

Palliative care involvement in hospitalisation has increased $28 \%$ from 2011 to $2016 .{ }^{6}$ More than half of patients may not have had the opportunity to discuss end-of-life care wishes or have them implemented. ${ }^{7}$ As a consequence, many patients undergo futile or inappropriate interventions. ${ }^{7}$ Up to $25 \%$ of intensive care beds are occupied by patients receiving potentially inappropriate care ${ }^{8}$ Similarly, about a quarter of health budgets is spent on inpatient care during the last 18 months of life without any discernible extension on overall survival or improvement in quality of life. ${ }^{8}$

The institutionalised manner in which dying is managed is often at odds with the home death that most Australians wish for if they were to develop a terminal illness. To achieve a death that is consistent with patients' wishes, with respect to location, being surrounded by family and friends, free from pain and with medical support when needed, planning should be initiated well before the end of life, while people are still competent to make decisions. ${ }^{9}$

\section{ACP reduces inappropriate hospitalisations and increases palliative care involvement}

There is evidence that ACP improves end-of-life care, reduces the rate of hospitalisations and ambulance calls, and increases referrals to specialist palliative care services. ${ }^{10,11}$ Earlier initiation of appropriate palliative care improves patients' symptoms and mood, reduces undesired use of invasive interventions and life-sustaining treatments, lowers the likelihood of in-hospital death, sustains a higher quality of life and decreases costs. ${ }^{12}$ Furthermore, an Australian study of ACP conducted in hospitals showed that ACP improves patient and family satisfaction, and alleviates anxiety in relatives of hospitalised patients. ${ }^{13}$ 


\section{ACP is uncommon}

Although ACP has existed as a concept for decades, and despite the evidence of benefits, its uptake into routine practice and discussion has been slow. The prevalence of ACP in Australia is not well reported, but it appears to be low. One estimate of ACP prevalence in Australia is no more than $14 \%$ of the population. ${ }^{14}$

\section{General practices are ideally placed for ACP}

Planning for the future is best discussed at a time when health is stable, and thus the primary care setting is ideal. The Royal Australian College of General Practitioners' position statement affirms the ongoing and trusting relationships that general practitioners (GPs) have with their patients, and acknowledges that general practice is an important setting for initiating and promoting ACP. ${ }^{1}$

\section{Barriers to ACP in general practice}

Several barriers to ACP in general practice have been identified. These relate to healthcare professionals, patients or the health system.

\section{Healthcare professionals}

Some GPs may perceive that patients are not willing or able to face discussions around death and dying. ${ }^{15}$ The process of discussing ACP may be seen as depriving a patient of hope or damaging the GPpatient relationship. ${ }^{16} \mathrm{GPs}$ also report trepidation in dealing with changing patient preferences, and the emotional impact and discomfort of having ACP discussions. ${ }^{17}$ Furthermore, some GPs have expressed doubts regarding the content and practical availability of ACP documentation at the time when

Box 1. Different types of documents involved in advance care planning (ACP) ${ }^{27}$

\section{Advance Care Plan}

ACP discussions can result in the creation of a document (or video or recording) containing the patient's preferences and values. This is called an Advance Care Plan. These plans can be written by the patient or by a substitute decision-maker* in cases where the patient does not have decision-making capacity. Even patients with diminished decision-making capacity could be assisted to create an Advance Care Plan.

\section{Advance Care Directives (ACDs; also known as Advance Directives or Advance Health Directives)}

These are formal documents that form a subset of Advance Care Plans. Depending on the state and territory, there may be statutory ACDs that are covered by a specific legislation or ACDs that are covered under the common law.

a. Statutory ACDs. Many states and territories have specific legislation governing statutory ACDs. Some allow the patient to refuse specific medical treatments or express their preferences and values. Others may allow the patient to formally appoint substitute decision-makers. ${ }^{*}$ Some allow for expression of preferences and appointment of substitute decision-makers. Statutory ACDs are legally binding. Some jurisdictions clarify that witnesses to ACDs must be independent of the patient and cannot be direct beneficiaries of the patient's assets, or substitute decision-makers, health practitioners looking after the patient or paid professional carers.

b. Non-statutory ACDs (ie ACDs covered under the common law). Some states and territories may not have specific legislations regarding ACP. For instance, at the time of writing, NSW does not have specific legislation for ACDs. Under the common law, patients in NSW can still create a legally binding ACD containing their values and preferences. Of note, common law ACDs are legally binding in only some states and territories.

${ }^{*} A$ substitute decision-maker is appointed or identified by law to make decisions when a person's decisionmaking capacity is impaired. Examples of an appointed substitute decision-maker include enduring guardians, while substitute decision-makers identified by the law include partners/spouses, unpaid carers and family members/relatives.

For further information on the legal aspects of ACP for each state and territory, refer to:

- www.advancecareplanning.org.au/for-health-and-care-workers/legal-requirements

- https://end-of-life.qut.edu.au/advance-directives

end-of-life decisions need to be made. A busy workload, inadequate training, and lack of time and remuneration have also discouraged clinicians from involvement in ACP. ${ }^{18}$

\section{Patients}

Patient-related barriers include a lack of awareness of ACP and a reluctance to communicate end-of-life issues. ${ }^{19,20}$ Some patients, seeing themselves as healthy, might view ACP as irrelevant. ${ }^{19}$ They may express the view that medical technology will prolong a healthy life, and regard death as a matter of fate. Others might regard ACP as unnecessary because they believe, rightly or wrongly, their end-oflife wishes to be already known to their family and doctors. ${ }^{20}$

The uptake of Advance Care Directives (ACDs) in culturally and linguistically diverse populations is lower, and there is also a correspondingly limited consideration of these groups in policy development. ${ }^{21}$

\section{The health system}

Given the wide range of services providing end-of-life care, service fragmentation has been acknowledged as a major barrier to achieving quality outcomes for those at the end of life. ${ }^{22}$ There have been calls for an improvement in collaboration among healthcare providers in initiating and maintaining the ACP process for patients.

Patients' preferences can change, so these should be reviewed on a regular basis and not assumed to be static. ${ }^{23}$ Preferences may also be based on incorrect or insufficient information or be documented in vague, incomplete terms. Completed ACDs may be difficult to access when needed. As a result of the lack of standardisation and clarity at the time of decision making, doctors and substitute decision-makers may disregard or feel incapable of enacting expressed wishes. ${ }^{19}$

\section{Integrating ACP into everyday general practice}

We propose a three-step process that general practices could use to integrate ACP into routine clinical care. 


\section{Commitment by the whole practice to incorporate ACP into clinical care}

Successful implementation of ACP requires a systematic approach. ${ }^{18}$ The entire practice team - including the doctors, nurses, practice manager and administrative staff - should have a shared understanding of the importance and value of ACP. Team meetings are essential to achieving this. There should be agreement on:

- the role of each team member, especially if practice nurses or administration staff are involved.

- documents that will be used to support the discussions. This may include ACD templates, brochures and other information booklets.

- how ACP will be documented, including an agreement on how and where the discussions will be documented. An alert could be created in the practice software to remind the clinician about the presence or lack of an active ACD.

- funding. Currently, there is no specific Medicare Benefits Schedule (MBS) item number for ACP. This means that practices need to use existing MBS items to fund ACP. This could be conducted and billed as part of a routine general practice consultation or series of consultations. If this adds pressure to already busy general practice schedules, ACP could be introduced as part of the Medicare Health Assessment for Older Persons (75+) or the chronic disease management plan review. A helpful document outlining appropriate billing options is available on the Advance Care Planning Australia website at (www.advancecareplanning. org.au/docs/default-source/acparesource-library/acpa-fact-sheets/ acpa_mbs-factsheet_2018_online. pdf?sfvrsn=33).

It might be useful to collect data at this stage to document the extent of ACP that is going on in the practice. This would provide a useful baseline to compare against once the practice has implemented a systematic approach to ACP. Data collection could be simple and involve an audit of patient records to determine the presence of ACDs, Advance Care Plans or documentation of ACP discussions by health professionals over a period of time (eg previous 12 months). Keen practices could supplement this information by conducting a waiting room survey asking patients whether they have ever completed an ACD or Advance Care Plan or appointed a substitute decision-maker.

\section{Building capacity for ACP in the practice}

GPs should ensure that they have effective communication skills to discuss end-of-life care issues and have a good understanding of ACP. Examples of education and training options available for GPs are listed in Box 2. There may also be seminars and workshops organised by the local primary health network ( $\mathrm{PHN}$ ) on ACP and communication skills pertaining to end-of-life care. The PHN may also be able to support the practice by providing copies of the ACD forms (physical or electronic), brochures and patient workbooks.

Practice nurses are interested in and enthusiastic about receiving additional training so that they could become more involved in discussing ACP with patients. ${ }^{24}$ The involvement of the nurses could allow GPs to focus on the 'medical' aspects, clarifying patients' concerns and signing or witnessing ACDs or other documents. A free online training program has been developed to support Australian practice nurses in initiating ACP and conducting supportive care assessments (www.caresearch.com.au/advance).

\section{Implementing and optimising the ACP process}

The next step is to implement and optimise the ACP process. The different elements are discussed below.

Identifying suitable patients
While it could be argued that ACP is
relevant for every adult, it is likely to be
more relevant to certain groups of patients.
These include elderly patients, especially
those who are frail or have multiple chronic
diseases, patients recently diagnosed with
a condition that is likely to lead to the loss
of decision-making capacity, and people
diagnosed with potentially life-limiting
illness. Recent hospital admissions or
transfer to an aged-care facility are also
indicators for suitability of ACP discussion.
The 'surprise question' is a useful tool
for identifying patients who might be
suitable for ACP. Here, clinician asks the
question, 'Would I be surprised if this
patient died in the next 6-12 months?'
ACP could be considered if the answer
is 'No'.25 Systematic tools, such as the
Supportive and Palliative Care Needs
Indicator Tool (www.spict.org.uk), are also
available to assist in identifying patients
who may have poor prognosis.
ACP may also be relevant for people
without close relatives or friends who
could be trusted to make decisions
for them, and people with uncommon
treatment preferences (eg people of certain
faiths that prohibit blood transfusion).

Box 2. Education and training for general practitioners on advance care planning and communication skills pertaining to end-of-life care

- The Advance Project (www.caresearch.com.au/advance)

- The Royal Australian College of General Practitioners online modules available through gplearning

- ThinkGP module on ACP (https://thinkgp.com.au/education/advance-care-planningprimary-care)

- Advance Care Planning Australia educational resources (www.advancecareplanning.org.au/ for-health-and-care-workers/workshops-and-specialised-training)

- Clinical practice guidelines: communicating prognosis and end of life issues (www.mja.com. au/journal/2007/186/12/clinical-practice-guidelines-communicating-prognosis-and-endlife-issues-adults)

- Caresearch (www.caresearch.com.au/caresearch/tabid/3882/Default.aspx)

- Program of Experience in the Palliative Approach (PEPA; https://pepaeducation.com)

- ELDAC - End of life directions for aged care - a national specialist palliative care and ACD advisory service (www.eldac.com.au/)

- PalliAGED - A collection of palliative care evidence and resources (www.palliaged.com.au) 


\section{Initiating ACP}

GPs whom their patients know and trust are well placed to discuss issues around death and dying. ${ }^{26}$ Picking a suitable moment to initiate ACP may be difficult. It is important to recognise that ACP is not a 'once only' event. It is a process, and patients might require several visits to comprehend and process information and review pre-existing ACDs.

While some patients initiate ACP, many do not. ${ }^{18}$ In such cases, the GP may choose to bring up the topic opportunistically during a consultation. It is useful to look for a cue - for example, when the patient discusses their experience of visiting a relative with dementia. Other natural triggers for bringing up the topic include when a patient has been diagnosed with a new condition or there have been significant changes to their health or living situation. ACP could also be discussed if the topic of writing or changing a will comes up. ACP could be introduced during routine consultations using a standard phrase in order to normalise the topic (Box 3), or during routine age-specific health assessments or chronic disease management plan reviews. Many GPs also have connections with residential aged care homes and regional hospitals, and the initiation of ACP discussions could occur in these settings as well (eg within several weeks of admission).

Some patients may decline the invitation, but many welcome the opportunity to discuss their concerns and learn more about ACP. In this case,

\section{Box 3. Useful phrases for introducing advance care planning to patients during a routine consultation ${ }^{28}$}

'Some people are worried about things that may or may not happen in the future. It can help to talk about this.'

'Have you ever talked about your wishes and values for medical treatment and care in case you were suddenly injured or became too unwell to speak for yourself?

'It's often easier to talk through tough decisions when there isn't a crisis.'

'Is this something that you would like to discuss further?' the patient's concerns and questions about their health could be addressed, and their needs regarding ACP explored further. A useful tool has been developed to enable GPs and nurses to approach this systematically and can be accessed at the Advance Project website (www.caresearch. com.au/advance).

The patient could then be provided with written information on ACP and advised to return for further discussion after they have had time to clarify their thoughts. Patients should be encouraged to speak to their loved ones about their wishes and concerns. Including family and decisionmakers in the ACP process creates a shared understanding of what is most important to the patient.

Subsequent consultations can focus on evaluating a patient's understanding of their condition and care, providing further information and answering questions. Some individuals may wish to appoint a substitute decision-maker or document their preferences into an ACD. The GP or nurse could assist by reviewing the document and checking the patient's understanding of what is written. The GPs may also be involved in witnessing or countersigning the documents.

Once ACP has been implemented into the practice, it is important to take time to reflect and see if it has been implemented well, and determine what impact it has made on patient care. It is useful to conduct an audit of the medical records at this stage. Comparison with the baseline results will allow the practice to determine if it has been successful in encouraging more patients to engage in ACP. Very keen practices may choose to supplement this information with a waiting room survey. Collating the data and presenting it to the entire practice team at regular meetings will provide invaluable feedback to the team members and encourage them to continue on with ACP and having conversations about end-of-life care.

\section{Maximising ACP utility}

A challenge with ACP is communicating this information to the point of care where it may be required, especially in emergency situations. This is most apparent in urban areas where there may be numerous hospitals in the surrounding area. Once ACP is completed, we would encourage that this is communicated to other doctors who are closely involved in the care of that individual. For patients at risk of lifethreatening events, a hospital information pack could be prepared, complete with a recent medication list and ACP. A copy of the ACP could then be faxed to the ambulance service and local hospital. The My Health Record system holds promise in terms of allowing for an online repository for ACP documentation, yet at this point further development is required to allow access across all health services.

\section{Conclusion}

General practice has an important role in ACP. The commitment and involvement of the whole practice and the building of capacity in ACP, followed by systematic implementation and optimisation of the ACP process, will assist in successfully incorporating ACP into routine clinical care.

\author{
Authors \\ Michael Tran MBBS BSc (Med) (Hons), FRACGP, \\ General Practitioner, Church Street Medical Practice, \\ Newtown, NSW \\ Matthew Grant MBBS, MBioethics, FRACGP, \\ FAChPM, Palliative Medicine Physician, St Vincent's \\ Hospital, Melbourne, Vic; Research Fellow, VCCC \\ Palliative Medicine Research Group \\ Josephine Clayton MBBS, PhD, FAChPM, FRACP, \\ Director, HammondCare Centre for Learning \& \\ Research in Palliative Care; Professor of Palliative \\ Care, Sydney Medical School, University of Sydney; \\ Senior Staff Specialist Physician in Palliative \\ Medicine, HammondCare, Greenwich Hospital; \\ Director, National Advance Project \\ Joel Rhee BSc (Med), MBBS (Hons), GCULT, PhD, \\ FRACGP, Associate Professor in General Practice, \\ General Practice Academic Unit, School of Medicine, \\ University of Wollongong; General Practitioner, \\ HammondCare Centre for Positive Ageing \& Care. \\ jrhee@uow.edu.au \\ Competing interests: Dr Grant reports he works as a \\ Clinical Advisor for Australian Digital Health Agency \\ outside the submitted work. \\ Funding: None. \\ Provenance and peer review: Commissioned, \\ externally peer reviewed.
}

\section{References}

1. RACGP. Position Statement: Advance care planning should be incorporated into routine general practice. Melbourne: RACGP, 2012. Available at www.racgp.org.au/policy/clinical [Accessed 27 September 2018]. 
2. Australian Institute of Health and Welfare (AIHW). Older Australia at a glance. Canberra: AlHW, 2017. Available at www.aihw.gov.au/reports/olderpeople/older-australia-at-a-glance/contents/ demographics-of-older-australians/australias-changing-age-and-gender-profile [Accessed 27 September 2018]

3. Swerissen H, Duckett S. Dying Well. Carlton, Vic: Grattan Institute, 2014

4. Rosenwax LK, McNamara BA, Murray K, McCabe RJ, Aoun SM, Currow DC. Hospital and emergency department use in the last year of life: A baseline for future modifications to end-of-life care. Med J Aust 2011;194(11):570-73.

5. Australian Institute of Health and Welfare. Australia's Health 2016 - End-of-life care. Australia's Health Series no. 15. Cat no. AUS 199. Canberra: AlHW, 2016; p. 1-12.

6. Australian Institute of Health and Welfare. Palliative care services in Australia. Canberra: AlHW, 2018. Available at www.aihw.gov.au/ reports/palliative-care-services/palliativecare-services-in-australia/contents/summary [Accessed 27 September 2018].

7. Walling AM, Asch SM, Lorenz KA, et al. The quality of care provided to hospitalized patients at the end of life. Arch Intern Med 2010;170(12):1057-63. doi: 10.1001/archinternmed.2010.175.

8. van Weel C, Michels J. Dying, not old age, to blame for costs of health care. Lancet 1997;350(9085):1159-60. doi: 10.1016/S01406736(97)08312-8.

9. Cancer Council Australia. Facing end of life: A guide for people dying with cancer, their families and friends. Sydney: Cancer Council Australia, 2017.

10. Brinkman-Stoppelenburg A, Rietjens JA, van der Heide A. The effects of advance care planning on end-of-life care: A systematic review. Palliat Med 2014;28(8):1000-25 doi: 10.1177/0269216314526272.
11. Caplan GA, Meller A, Squires B, Chan S, Willett W. Advance care planning and hospital in the nursing home. Age Ageing 2006;35(6):581-85. doi: 10.1093/ageing/afl063.

12. Abel J, Pring A, Rich A, Malik T, Verne J. The impact of advance care planning of place of death, a hospice retrospective cohort study. BMJ Support Palliat Care 2013;3(2):168-73. doi: 10.1136/ bmjspcare-2012-000327.

13. Detering KM, Hancock AD, Reade MC, Silvester W. The impact of advance care planning on end of life care in elderly patients: Randomised controlled trial. BMJ 2010;340:c1345. doi: 10.1136/bmj.c1345.

14. White B, Tilse C, Wilson J, et al. Prevalence and predictors of advance directives in Australia. Intern Med J 2014;44(10):975-80. doi: 10.1111/imj.12549.

15. Thompson TD, Barbour RS, Schwartz L. Health professionals' views on advance directives: A qualitative interdisciplinary study. Palliat Med 2003;17(5):403-09. doi: 10.1191/0269216303pm784oa

16. Boyd K, Mason B, Kendall M, et al. Advance care planning for cancer patients in primary care: A feasibility study. Br J Gen Pract 2010;60(581):e449-58. doi: 10.3399/ bjgp10X544032.

17. Pfeifer MP, Sidorov JE, Smith AC, Boero JF, Evans AT, Settle MB. The discussion of end-oflife medical care by primary care patients and physicians: A multicenter study using structured qualitative interviews. The EOL Study Group. J Gen Intern Med 1994;9(2):82-88.

18. Rhee JJ, Zwar NA, Kemp LA. Uptake and implementation of Advance Care Planning in Australia: Findings of key informant interviews. Aust Health Rev 2012;36(1):98-104. doi: 10.1071/ AH11019.

19. Scott IA, Mitchell GK, Reymond EJ, Daly MP. Difficult but necessary conversations: The case for advance care planning. Med J Aust 2013;199(10):662-66.
20. Schickedanz AD, Schillinger D, Landefeld CS, Knight SJ, Williams BA, Sudore RL. A clinical framework for improving the advance care planning process: Start with patients' self-identified barriers. J Am Geriatr Soc 2009;57(1):31-39. doi: 10.1111/j.15325415.2008.02093.x.

21. Johnstone MJ, Kanitsaki O. Ethics and advance care planning in a culturally diverse society. J Transcult Nurs 2009;20(4):405-16. doi: 10.1177/1043659609340803.

22. Senate Community Affairs References Committee (SCARC). Palliative care in Australia. Report to the Senate, Australian Government. Canberra: SCARC, 2012.

23. Danis M, Garrett J, Harris R, Patrick DL. Stability of choices about life-sustaining treatments. Ann Intern Med 1994;120(7):567-73.

24. Fan E, Rhee JJ. A self-reported survey on the confidence levels and motivation of New South Wales practice nurses on conducting advance-care planning (ACP) initiatives in the general-practice setting. Aust J Prim Health 2017;23(1):80-86. doi: 10.1071/PY15174.

25. Reymond L, Cooper K, Parker D, Chapman M. End-of-life care: Proactive clinical management of older Australians in the community. Aust Fam Physician 2016;45(1):76-78.

26. Mitchell GK. End-of-life care for patients with cancer. Aust Fam Physician 2014;43(8):514-19.

27. The Australian Health Ministers' Advisory Council (AHMAC). A national framework for advance care directives. Canberra: Australian Government Department of Health and Ageing, 2011.

28. Clayton JM, Hancock KM, Butow PN, et al. Clinical practice guidelines for communicating prognosis and end-of-life issues with adults in the advanced stages of a life-limiting illness, and their caregivers. Med J Aust 2007;186(12 Suppl):S77, S9, S83-108. 